1 Observatoire National Interministériel de la Sécurité Routière. Bilan annuel statistiques et commentaires. Paris: Ministère des Transports, 1999. Horne JA, Reyner LA. Sleep related vehicle accidents. BMJ 1995;310:565-7.

3 Philip P, Ghorayeb I, Stoohs R, Menny JC, Dabadie P, Bioulac B, et al. Determinants of sleepiness in automobile drivers. $J$ Psychosomatic Res 1996; $41: 279-88$
4 Philip P, Taillard J, Guilleminault C, Quera Salva MA, Bioulac B, Ohayon $\mathrm{M}$. Long distance driving and self induced sleep deprivation among automobile drivers. Sleep 1999;22:475-80.

5 Biecheler MB, Filou C, Fontaine H. Conduite automobile et accidents liés à l'alcool. Références et résultats 1985 et 1995. Arceuil: INRETS Publishers, 1995.

(Accepted 21 December 2000)

\title{
Relation between socioeconomic status and tumour stage in patients with breast, colorectal, ovarian, and lung cancer: results from four national, population based studies
}

\author{
David H Brewster, Catherine S Thomson, David J Hole, Roger J Black, Paul L Stroner, \\ Charles R Gillis on behalf of the Scottish Cancer Therapy Network
}

Scottish Cancer Intelligence Unit, Information and Statistics Division, Trinity Park House, Edinburgh EH5 3SQ David H Brewster director of cancer registration in Scotland

Catherine S

Thomson

senior statistician

Roger J Black

head

Paul L Stroner

coordinator of the

Scottish Cancer

Therapy Network

West of Scotland

Cancer Surveillance

Unit, Department of

Public Health,

University of

Glasgow, Glasgow

G12 8RZ

David J Hole

deputy director

Charles R Gillis

director

Correspondence to: D H Brewster

David.Brewster@

isd.csa.scot.nhs.uk

BMJ 2001;322:830-1

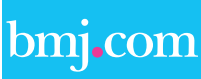

A table showing the availability of medical records by socioeconomic status appears on the BMJ's website
Although there is evidence that patients with cancer from deprived communities in Scotland might present with more advanced disease, ${ }^{1-3}$ this finding has not been replicated in every study. ${ }^{4}$ Using data from four population based audits, we investigated whether there is any relation between socioeconomic status and tumour stage at presentation in patients with breast, colorectal, ovarian, and lung cancer.

\section{Participants, methods, and results}

For each audit potential study populations were identified from the Scottish Cancer Registry, and data were abstracted from medical records. The years of diagnosis for patients with breast, colorectal, ovarian, and lung cancer were 1993, 1993, 1992-4, and 1995, respectively.

The staging details examined were: pathological size, pathological nodal status, and metastatic status for breast cancers; Dukes' stage for colorectal cancers; Fédération Internationale de Gynécologie et d'Obstétrique stage for ovarian cancers; and a simple extent of disease classification based on clinical findings or investigations for lung cancers (as only $11 \%$ of cases had surgical resection), or both.

Medical records were available for 2518 patients with breast cancer, 2778 with colorectal cancer, 1387 with ovarian cancer, and 3855 with lung cancer, representing more than $90 \%$ of potentially eligible cases for each of the four cancer sites. A higher proportion of records was unobtainable for deprived than for affluent patients with lung cancer $(11.7 \%$ v $7.0 \%, \mathrm{P}<0.001)$ (see table on website). No significant differences were found in availability of medical records by deprivation grouping for the other cancers.

The table shows the distributions of variables for tumour staging by cancer site and deprivation grouping. P values for associations between the staging variables and deprivation were similar when unknown stages were excluded. We found no evidence that patients from deprived communities were likely to present with more advanced disease for breast or colorectal cancer. For ovarian cancer there was a possibility that deprived patients may have more advanced disease (see table); however, deprived patients with lung cancer were more likely to present with localised disease (see table). Multivariate analyses, performed using log linear modelling, showed no evidence of age dependent relations between stage of disease and deprivation. The four age groups used for these analyses differed by cancer site because they were predefined by different specialist groups-for example, the breast cancer specialists included a category for screening age group (50-64 years).

\section{Comment}

We found no consistent evidence that patients from deprived communities present with more advanced disease for breast, colorectal, ovarian, or lung cancer. Despite the introduction of breast screening and differential uptake by socioeconomic status, ${ }^{5}$ our results for breast cancer remain similar to those of Carnon et al. $^{4}$ However, another recent but smaller study from the west of Scotland found that women from deprived areas were more likely to present with locally advanced or metastatic disease. ${ }^{3}$ Our result for colorectal cancer conflicts with those of a study from Tayside, although the latter was based on cases for which there was a record of disease, and so not population based, and excluded patients with distant metastases. ${ }^{2}$ The result for ovarian cancer was of borderline significance, although patients with stage unknown had a generally worse prognosis than those with stage IV disease, presumably reflecting inoperability. The greater likelihood of deprived patients with lung cancer presenting with localised disease could be an artefact resulting from differential availability of medical records across the socioeconomic groupings or, owing to comorbidity, less intensive investigation of these patients leading to less accurate data for staging. Alternatively, it might reflect a lower threshold for investigation and referral in patients from deprived communities presenting with suspicious symptoms, because they are more likely to be current smokers. Further research is needed to investigate the contribution of tumour, host, and treatment related factors to outcome. 
Relation between socioeconomic status and tumour stage in patients with breast, ovarian, colorectal, and lung cancer. Values are numbers (percentages)

\begin{tabular}{|c|c|c|c|c|}
\hline & \multicolumn{3}{|c|}{ Deprivation group* } & \multirow[b]{2}{*}{ Total } \\
\hline & Affluent & Middle & Deprived & \\
\hline Breast cancer† & $\mathrm{n}=548$ & $n=1605$ & $n=364$ & $\mathrm{n}=2517$ \\
\hline \multicolumn{5}{|l|}{ Tumour size $(\mathrm{mm})$ : } \\
\hline $0-20$ & $271(49.5)$ & $730(45.5)$ & $166(45.6)$ & $1167(46.4)$ \\
\hline $21-50$ & $124(22.6)$ & $409(25.5)$ & $109(29.9)$ & $642(25.5)$ \\
\hline$>50$ & $14(2.6)$ & $49(3.1)$ & $13(3.6)$ & $76(3.0)$ \\
\hline Unknown & $139(25.4)$ & $417(26.0)$ & $76(20.9)$ & $632(25.1)$ \\
\hline Significance & \multicolumn{4}{|c|}{$\chi^{2}=9.89, d f=6, P=0.13$} \\
\hline \multicolumn{5}{|l|}{ Node status: } \\
\hline Positive & $144(26.3)$ & $467(29.1)$ & $111(30.5)$ & $722(28.7)$ \\
\hline Inadequate negative sampleł & $58(10.6)$ & $178(11.1)$ & $31(8.5)$ & $267(10.6)$ \\
\hline Negative§ & $208(38.0)$ & $523(32.6)$ & $128(35.2)$ & $859(34.1)$ \\
\hline Unknown & $138(25.2)$ & $437(27.2)$ & $94(25.8)$ & $669(26.6)$ \\
\hline Significance & \multicolumn{4}{|c|}{$\chi^{2}=7.79, \mathrm{df}=6, \mathrm{P}=0.25$} \\
\hline \multicolumn{5}{|l|}{ Metastatic status at presentation } \\
\hline M0 & $517(94.3)$ & $1492(93.0)$ & $331(90.9)$ & $2340(93.0)$ \\
\hline M1 & $31(5.7)$ & $113(7.0)$ & $33(9.1)$ & $177(7.0)$ \\
\hline Significance & \multicolumn{4}{|c|}{$\chi^{2}=3.89, d f=2, P=0.14$} \\
\hline Colorectal cancer† & $\mathrm{n}=590$ & $\mathrm{n}=1734$ & $n=453$ & $\mathrm{n}=2777$ \\
\hline \multicolumn{5}{|l|}{ Dukes' stage: } \\
\hline A & $61(10.3)$ & $149(8.6)$ & $38(8.4)$ & $248(8.9)$ \\
\hline B & $202(34.2)$ & $576(33.2)$ & $156(34.4)$ & $934(33.6)$ \\
\hline $\mathrm{C}$ & $130(22.0)$ & $415(23.9)$ & $97(21.4)$ & $642(23.1)$ \\
\hline 'D' & $117(19.8)$ & $377(21.7)$ & $101(22.3)$ & $595(21.4)$ \\
\hline Unknown & $80(13.6)$ & $217(12.5)$ & $61(13.5)$ & $358(12.9)$ \\
\hline Significance & \multicolumn{4}{|c|}{$\chi^{2}=4.74, d f=8, P=0.79$} \\
\hline Ovarian cancer† & $\mathrm{n}=304$ & $n=856$ & $n=226$ & $\mathrm{n}=1386$ \\
\hline \multicolumn{5}{|c|}{ Fédération Internationale de Gynécologie et d'Obstétrique stage: } \\
\hline I & $73(24.0)$ & $191(22.3)$ & $33(14.6)$ & $297(21.4)$ \\
\hline II & $30(9.9)$ & $77(9.0)$ & $14(6.2)$ & $121(8.7)$ \\
\hline III & $126(41.4)$ & $388(45.3)$ & $108(47.8)$ & $622(44.9)$ \\
\hline IV & $51(16.8)$ & $131(15.3)$ & $44(19.5)$ & $226(16.3)$ \\
\hline Unknown & $24(7.9)$ & $69(8.1)$ & $27(11.9)$ & $120(8.7)$ \\
\hline Significance & \multicolumn{4}{|c|}{$\chi^{2}=14.96, d f=8, P=0.06$} \\
\hline Lung cancer & $\mathrm{n}=534$ & $\mathrm{n}=2371$ & $\mathrm{n}=950$ & $\mathrm{n}=3855$ \\
\hline \multicolumn{5}{|l|}{ Clinical stage: } \\
\hline Localised & $152(28.5)$ & $758(32.0)$ & $342(36.0)$ & $1252(32.5)$ \\
\hline Regional & $134(25.1)$ & $628(26.5)$ & $214(22.5)$ & 976 (25.3) \\
\hline Distant & $183(34.3)$ & 726 (30.6) & $295(31.1)$ & $1204(31.2)$ \\
\hline Unknown & $65(12.2)$ & $259(10.9)$ & $99(10.4)$ & $423(11.0)$ \\
\hline
\end{tabular}

*Patients were assigned to a 1991 census derived Carstairs deprivation category based on their postcode sector of residence at diagnosis. Carstairs deprivation categories: 1 and 2, affluent; 3, 4, and 5, middle; 6 and 7 , deprived.

†Deprivation score could not be assigned for one case.

†Represents 1, 2, 3, or unknown number of nodes sampled, all negative.

§Represents 4 or more nodes sampled or axillary clearance, all negative.

We thank Professor Colin McArdle and his surgical colleagues in the west of Scotland who allowed their data from a previous audit to be used in the Scottish Cancer Therapy Network's national audit of colorectal cancer and the many other clinicians in Scotland who contribute to the network's audits.

Contributors: DHB initiated the analysis, but all the authors were involved in specifying the analysis and interpretation of the results. CST and DJH carried out the analyses. DHB wrote the first draft of the manuscript, which was modified to incorporate comments from all the other authors; he will act as guarantor.

Funding: The Scottish Cancer Therapy Network is funded by grants from the Clinical Resource and Audit Group and the Chief Scientist Office, both of the Scottish Executive Health Department. The views expressed, however, are those of the authors.

Competing interests: None declared.

1 Lamont DW, Symonds RP, Brodie MM, Nwabineli NJ, Gillis CR. Age, socioeconomic status and survival from cancer of the cervix in the West socioeconomic status and survival from cancer of
of Scotland 1980-87. Br J Cancer 1993;67:351-7.

2 Ionescu MV, Carey F, Tait IS, Steele RJC. Socioeconomic status and stage at presentation of colorectal cancer. Lancet 1998;352:1439.

3 Macleod U, Ross S, Gillis C, McConnachie A, Twelves C, Watt GCM. Socio-economic deprivation and stage of disease at presentation in women with breast cancer. Ann Oncol 2000;11:105-7.
4 Carnon AG, Ssemwogerere A, Lamont DW, Hole DJ, Mallon EA, George WD, et al. Relation between socioeconomic deprivation and pathological prognostic factors in women with breast cancer. BMJ 1994;309:1054-7.

5 McLaren GL, Bain MRS. Deprivation and health in Scotland: insights from NHS data. Edinburgh: ISD Scotland, 1998.

(Accepted 13 December 2000)

\section{Endpiece}

\section{Oh yes}

Dud: So would you say you've learned from your mistakes?

Pete: Oh yes, I'm sure that I could repeat them exactly.

Peter Cook quoted by Brian Eno in The diary of Brian Eno,

London: Faber \& Faber, 1996 